\title{
Capacity constraints, Mergers and Collusion
}

\author{
Olivier Compte*, Frédéric Jenny**, Patrick Rey**a
}

November 9, 2003

\begin{abstract}
The objective of this paper is two-fold: to contribute to the analysis of tacit collusion in Bertrand supergames with (asymmetric) capacity constraints and, from a more applied perspective, to bring a new light on merger analysis and provide useful guidelines for competition policy, taking into account dynamic aspects of competition. It is well-known that capacity constraints affect tacit collusion, as they limit both incentives to deviate (e.g., to undercut rivals) and retaliation possibilities. However, most studies have so far focused on symmetric situations, where all firms have the same capacity, which leads to ambiguous and unintuitive results but also considerably limits the scope of application. Studying asymmetric situations makes it possible to analyze the impact of changes in the distribution of these capacities (expansions, but also mergers, split-offs, transfers, ...) and to provide guidelines for competition policy and particularly for merger policy. These guidelines, which differ substantially from those inspired by more static analyses, such as the Herfindahl or other standard concentration tests, are applied to a famous merger that took place in the French bottled water market, the Nestlé-Perrier merger case.

${ }^{*}$ CERAS-ENPC, Paris

** ESSEC, Paris

${ }^{* * *}$ University of Toulouse, GREMAQ and IDEI, Toulouse, and CEPR, London

JEL classification: K2; L4

Keywords: Capacity Constraints; Mergers; Collusion

${ }^{a}$ Correspondance address: Patrick Rey, IDEI, Université des Sciences Sociales, Place Anatole France, F-31042 Toulouse cedex, France. Tel: + 335611286 40; fax: + 33561128637 .

E-mail address: prey@cict.fr
\end{abstract}




\section{Introduction}

The objective of this paper is to analyse tacit collusion with (asymmetric) capacity constraints and, from a more applied perspective, to shed more light on merger analysis, taking into account dynamic aspects of competition.

Capacity constraints play a key role in the analysis of tacit collusion. Firms can indeed maintain collusive prices if they believe that undercutting their rivals would trigger a price war and thus harm future profits: the potential short-term gain from a deviation can then be outweighed by the long-run losses from the price war. Capacity constraints affect this insight in two ways: they reduce the incentives to deviate as well as the severity of price wars. Most studies on this issue have so far focused on symmetric situations, where all firms have the same capacity, ${ }^{1}$ or on duopolistic industries, which limits their scope of application. for example, restricting attention to symmetric situations allows to study the impact of a demand shock (which affects all firms' excess capacities) or of a change in the number of firms, ${ }^{2}$ but is not very helpful for merger analysis. ${ }^{3}$

\footnotetext{
${ }^{1}$ See e.g. Abreu (1986) for an analysis of symmetric Cournot supergames and Brock and Scheinkman (1985) for a first analysis of symmetric Bertrand supergames, later extended by Lambson (1987).

${ }^{2}$ Brock and Scheinkman (1985) for example show in a linear model that the highest sustainable per capita profit varies non-monotonically with the number of firms.

${ }^{3} \mathrm{~A}$ relevant analysis must moreover consider industries with at least three competitors (in the pre-merger situation). Davidson and Deneckere (1984) however provide a first exploration of the impact of mergers on collusion, using standard trigger strategies and exogenous market sharing rules, starting from a situation with symmetric capacities.
} 
Analysing tacit collusion in oligopolistic industries with asymmetric capacity constraints is unfortunately quite difficult. Lambson (1994), who offers one of the most advanced analyses in that direction, still only provides partial characterizations. ${ }^{4}$ A few studies, however, suggest that asymmetry in firms' capacities hurt tacit collusion. Mason, Phillips and Nowell (1992) note that in experimental duopoly games, cooperation is more likely when players face symmetric production costs. $^{5}$ In a Bertrand-Edgeworth setting, Lambson (1996) shows that introducing a slight asymmetry in capacities hurts tacit collusion; and Davidson and Deneckere (1984), (1990) and Pénard (1997) show that asymmetric capacities make collusion more difficult in duopolies. ${ }^{6}$ We explore this issue in further detail, and show that the introduction of asymmetric capacities makes indeed collusion more difficult to sustain when the aggregate capacity is limited - asymmetry may instead help

\footnotetext{
${ }^{4}$ Lambson shows for example that the optimal punishments are such that the firm with the largest capacity gets no more that its minmax profit, while smaller firms get more (except if firms are very patient) than their respective minmax profits. He also provides an upper bound on the punishments that can be inflicted on small firms using a particular class of penal codes (proportional to capacities).

${ }^{5}$ Relatedly, Bernheim and Whinston (1990) show that, in the absence of capacity constraints, tacit collusion is easier when firms have symmetric costs and market shares.

${ }^{6}$ Davidson and Deneckere study the use of grim-trigger strategies in a Bertrand setting, while Pénard relies on minmax punishments (which can be sustained if the asymmetry is small) in a linear Cournot setting; both papers also address capacity investment decisions, whereas we focus on the distribution of exogenous capacities. In a duopoly with sequential capacity choices, Benoît and Krishna (1991) show that the second mover cannot enhance its gains from collusion by choosing a capacity different from the first mover's capacity - however, their analysis relies on the assumption that firms share demand equally when charging the same price. Gertner (1994) develops a framework of "immediate responses", where firms can react at once to each other's price cuts, and shows that asymmetric capacities may prevent firms from colluding perfectly.
} 
collusion when the aggregate capacity is much larger than the market size.

We also address a distinct issue, which is the impact of changes in the distribution of capacities (mergers, split-offs, transfers, ...). ${ }^{7}$ For that purpose, in a model of repeated Bertrand competition, we ask the following question: given a distribution of capacities, for which values of the discount factor can firms sustain tacit collusion? As usual, collusion is sustainable when the discount factor is higher than a threshold, and we analyse the impact of changes in capacities on this minimal threshold. This analysis provides guidelines for competition policy and particularly for merger policy, which differ from the guidelines inspired by static analyses, such as the reference to Herfindahl or other standard concentration tests. The analysis also casts some doubts on standard "remedies" routinely used by competition authorities, such as transferring some assets of the merged firm to existing competitors. Finally, we apply those guidelines to the merger between Nestlé and Perrier - a famous European merger case.

The paper is organized as follows. Section 2 describes the model. Section 3 offers a complete characterization of a particular class of collusive equilibria, where firms keep constant - possibly asymmetric - market shares. ${ }^{8}$ Section 4 discusses the

\footnotetext{
${ }^{7}$ Fershtman and Pakes (1999) further explore the interaction between collusion and the industry structure, allowing for entry and exit as well as asymmetric sizes but restricting attention to a particular class of (markovian) pricing policies.

${ }^{8}$ These collusive equilibria are as effective as standard trigger equilibria (reversal to the static Nash equilibrium) or as the proportional penal codes equilibria analyzed by Lambson (1994).
} 
impact of asymmetry in the distribution (both for this particular class of equilibria and for the most general one) as well as of various changes in the distribution of capacities (mergers, split-offs, transfers). Section 5 applies the analysis to the Nestlé-Perrier merger. Except when otherwise mentioned, proofs are relegated to the Appendix.

\section{The model}

We consider a model of Bertrand-Edgeworth price competition with capacity constraints between $n$ firms. The demand side consists of a mass $M$ of infinitesimal buyers, each willing to buy one unit as long as the price does not exceed 1. Each firm $i$ has a constant unit cost, normalized to 0, and a limited capacity $k_{i}>0$. Without loss of generality, we assume $k_{1} \leq \ldots \leq k_{n}$, and denote by $k \equiv\left(k_{1}, \ldots, k_{n}\right)$ the distribution of capacities, by $K \equiv \sum_{i} k_{i}$ the total capacity and by $K_{-i} \equiv \sum_{j \neq i} k_{j}$ the total capacity of firm $i$ 's rivals. For a given distribution of capacities, firm $i$ 's relevant capacity is $\hat{k}_{i} \equiv \min \left\{k_{i}, M\right\}$ : if a firm can serve the entire market, it does not matter whether it can serve it two or three times; lastly, $\hat{K} \equiv \sum_{i} \hat{k}_{i}$ and $\hat{K}_{-i} \equiv \sum_{j \neq i} \hat{k}_{j}$

The monopoly price is $p^{m}=1$. Throughout the paper we refer to a competitive stage game, where firms simultaneously set their prices, which are perfectly 
observed by all buyers and firms; then, buyers go to the firm with the lowest price and decide whether or not to buy; if they are rationed they go to the next lowest priced firm, and so forth, as long as the price offered does not exceed their reservation price. ${ }^{9}$ If several firms charge the same price, consumers divide themselves as they wish between those firms. We denote by $\pi_{i}$ the profit obtained by firm $i$. We assume that competition is effective, i.e., in any Nash equilibrium expected aggregate profits are strictly lower than the monopoly profit, $\Pi^{m}$; this is the case if and only if the aggregate capacity of the firms is strictly larger than the market size $(K>M),{ }^{10}$ in which case $\Pi^{m}=M$. Lastly, we denote by $\underline{\pi}_{i} \equiv \max \left\{0, M-K_{-i}\right\}$ firm i's minmax profit.

To analyse tacit collusion, we consider the infinite repetition of this game, where all firms use the same discount factor $\delta \in(0,1)$ and maximize the expected sum of their discounted profits $\sum_{t \geq 1} \delta^{t-1} \pi_{i}^{t}$, where $\pi_{i}^{t}$ denotes firm $i$ 's profit at date $t$. To define collusion, we will refer to the (per period) value of an equilibrium, defined as the normalized expected sum of discounted profits that firms obtain along the equilibrium path: $V=(1-\delta) E\left[\sum_{t \geq 1} \delta^{t-1} \sum_{i} \pi_{i}^{t}\right] / \Pi^{m}$. A collu-

\footnotetext{
${ }^{9}$ Since buyers are identical, we do not need to be more specific about the rationing scheme.

${ }^{10}$ Firms' profits add up to $\Pi^{m}$ only if firms charge $p^{m}=1$ with probability 1 . If this is the case in equilibrium, then each firm must obtain a profit equal to $\pi_{i}=k_{i}$, which it can secure by slightly undercutting its rivals; but this cannot be true for all firms when the total capacity exceeds the market size. Conversely, when the total capacity does not exceed the market size, charging the monopoly price is a dominant strategy for each firm.
} 
sive equilibrium is a subgame perfect equilibrium of the infinitely repeated game whose value is strictly higher than the expected aggregate profit generated by any Nash equilibrium of the stage game, and we will say that collusion is sustainable when there exists a collusive equilibrium. We will also say that perfect collusion is sustainable if there exists an equilibrium with a value equal to the monopoly profit $\Pi^{m}$. Our goal is to characterize, for any distribution of capacities $k$, the lowest discount factor $\delta(k)$ for which (perfect) collusion is sustainable.

Characterizing the set of collusive equilibria is a difficult task, mainly because the maximal punishments also depend on the capacity distribution. One simple case is when small firms are not "too small", namely $K_{-n} \geq M$. In that case, any subset of $(n-1)$ firms can serve the entire market; the static Nash equilibrium yields zero profits and obviously constitutes the optimal punishment. Denoting by $\alpha_{i}$ the share of the market served by firm $i,{ }^{11}$ collusion can then be sustained if and only, for each firm $i=1, \ldots, n$ :

$$
\alpha_{i} \geq(1-\delta) \hat{k}_{i}
$$

Hence collusion is sustainable if and only if $\delta \geq 1-\max _{i}\left\{\alpha_{i} / \hat{k}_{i}\right\}$. This implies that the market shares that are most favourable to collusion are proportional to

\footnotetext{
${ }^{11}$ That is, $\alpha_{i}$ is the volume served by firm $i$. If the entire market is served, $\Sigma_{i} \alpha_{i}=M$. For simplicity we refer to $\alpha_{i}$ as firm $i$ 's market share, even though it represents a number of customers rather than a proportion of the market.
} 
the relevant capacities ${ }^{12}$ and, for those market shares, collusion is sustainable if and only if:

$$
\delta \geq \delta(k)=1-\frac{M}{\hat{K}}
$$

The sustainability of collusion then only depends on the aggregate relevant capacity, not on its distribution. ${ }^{13}$

\section{3. $\alpha$-equilibria}

The analysis is more difficult when small firms are indeed "small" $\left(K_{-n}<M\right)$. Therefore, we will focus in this section on a particular class of equilibria, where firms follow the same strategy and maintain constant market shares: for any distribution of market shares $\alpha=\left(\alpha_{1}, \ldots, \alpha_{n}\right)$ satisfying $0 \leq \alpha_{i} \leq k_{i}$ and $\sum_{i} \alpha_{i} \leq$ $M$, an $\alpha$-equilibrium will be such that in any equilibrium path, each firm $i$ obtains a share $\alpha_{i}$ of the market. ${ }^{14}$

We provide below a characterization of the lowest discount factor $\widetilde{\delta}(k, \alpha)$ for the existence of a collusive $\alpha$-equilibrium, as well as the minimal threshold $\delta^{*}(k)=\min _{\alpha} \widetilde{\delta}(k, \alpha)$ for the existence of at least one collusive $\alpha$-equilibrium (throughout this section, "equilibrium" will stand for " $\alpha$-equilibrium"). We will

\footnotetext{
${ }^{12} \max _{i}\left\{\alpha_{i} / \hat{k}_{i}\right\}$ is smallest when $\alpha_{i} / \hat{k}_{i}$ is the same for all firms, i.e., $\alpha_{i}=\hat{k}_{i} M / \hat{K}$.

${ }^{13} \mathrm{~A}$ redistribution of capacity may however affect the sustainability of collusion if it modifies firms' relevant capacities - see Sections 4 and 5.

${ }^{14}$ The restriction applies to equilibrium paths (including those that follow a deviation), not to possible deviations.
} 
focus on capacities such that $K_{-n}<M$, which implies $\hat{k}_{i}=k_{i}<M$ for $i<n$ (for $K_{-n} \geq M$, as well as for symmetric capacities, $\delta^{*}(k)=\delta(k)$ - see Comment 1 below).

\subsection{Necessary and sufficient conditions for collusion.}

The following Lemma identifies necessary and sufficient conditions for collusion:

Lemma 3.1. Fix $\alpha=\left(\alpha_{i}\right)_{i=1, \ldots, n}$ satisfying $0 \leq \alpha_{i} \leq k_{i}$ for $i=1, \ldots, n$ and $\sum_{i} \alpha_{i} \leq M$

i) If there exists a collusive $\alpha$-equilibrium, there exists a per period value $V$ satisfying, for $i=1, \ldots, n$ :

$$
\begin{gathered}
\alpha_{i} V \geq \underline{\pi}_{i}, \\
\alpha_{i} \geq(1-\delta) \hat{k}_{i}+\delta \alpha_{i} V .
\end{gathered}
$$

ii) If there exists $V$ satisfying conditions $\left\{\left(E_{i}\right),\left(P_{i}\right)\right\}_{i=1, \ldots, n}$, then there exists an $\alpha^{\prime}$-equilibrium with value $V^{\prime}$ for any value $V^{\prime} \in[V, 1]$ and any market shares $\alpha^{\prime}=\left(\alpha_{i}^{\prime}\right)_{i=1, \ldots, n}$ satisfying $\alpha_{i} \leq \alpha_{i}^{\prime} \leq k_{i}$ for $i=1, \ldots, n$ and $\sum_{i} \alpha_{i}^{\prime} \leq M$. In particular, perfect collusion $\left(V^{\prime}=1, \sum_{i} \alpha_{i}^{\prime}=M\right)$ is sustainable with any such market shares $\alpha^{\prime}$.

By construction, in a collusive $\alpha$-equilibrium, firm $i$ 's continuation payoff is proportional to its constant market share and thus of the form $\alpha_{i} V$, for some 
continuation value $V$. Condition $\left(P_{i}\right)$ asserts that firm $i$ 's continuation payoff cannot be worse than its minmax, while condition $\left(E_{i}\right)$ asserts that the threat of being "punished" by $\alpha_{i} V$ deters firm $i$ from deviating from the collusive path. These conditions are clearly necessary, but Lemma 3.1 establishes that, together, they ensure that the value $V$ (and any larger value) can be sustained as an $\alpha$ equilibrium.

Lemma 3.1 implies that the set of equilibrium values associated with a profile of market shares $\alpha$ is an interval of the form $[\underline{V}(K, \alpha, \delta), 1]$, where $\underline{V}(K, \alpha, \delta)$ is the smallest value satisfying conditions $\left(\left(P_{i}\right),\left(E_{i}\right)\right)_{i=1, \ldots, n}$. In particular, perfect collusion $(V=1)$ is sustainable whenever some collusion is sustainable; in the following, we will thus focus on the sustainability of perfect collusion.

\subsection{Collusion for given market shares}

Building on Lemma 3.1, we can easily characterize the sustainability of perfect collusion:

Proposition 3.2. Fix a distribution of market shares $\alpha=\left(\alpha_{i}\right)_{i=1, \ldots, n}$ satisfying $0 \leq \alpha_{i} \leq k_{i}$ for $i=1, \ldots, n$ and $\sum_{i} \alpha_{i}=M$; perfect collusion is sustainable as an $\alpha$ equilibrium if and only if $\delta \geq \widetilde{\delta}(k, \alpha)$, where the threshold $\widetilde{\delta}(k, \alpha)$ is characterized 
by

$$
\frac{\widetilde{\delta}}{1-\widetilde{\delta}}=\frac{\widetilde{\gamma}}{1-\widetilde{V}},
$$

where $\widetilde{\gamma}(k, \alpha) \equiv \max _{i}\left\{\hat{k}_{i} / \alpha_{i}\right\}-1$ and $\widetilde{V}(k, \alpha) \equiv \max _{i}\left\{\underline{\pi}_{i} / \alpha_{i}\right\}$.

Proof. From Lemma (3.1), perfect collusion is sustainable if and only if there exists $V$ satisfying $\left\{\left(E_{i}\right),\left(P_{i}\right)\right\}_{i=1, \ldots, n}$, which can be rewritten as (note that $\left(E_{i}\right)$ implies $\left.\alpha_{i}>0\right)$ :

$$
\begin{gathered}
V \geq \max _{i} \frac{\pi_{i}}{\alpha_{i}}=\widetilde{V}(k, \alpha) \\
(1-V) \frac{\delta}{1-\delta} \geq \max _{i} \frac{\hat{k}_{i}}{\alpha_{i}}-1=\widetilde{\gamma}(k, \alpha)
\end{gathered}
$$

Combining these two inequalities implies

$$
\frac{\delta}{1-\delta} \geq \frac{\widetilde{\gamma}(k, \alpha)}{1-V} \geq \frac{\widetilde{\gamma}(k, \alpha)}{1-\widetilde{V}(k, \alpha)}
$$

or $\delta \geq \widetilde{\delta}(k, \alpha)$. Conversely, if $\delta \geq \widetilde{\delta}(k, \alpha)$, then $V=\widetilde{V}(k, \alpha)$ satisfies the two sets of inequalities.

$\widetilde{V}(k, \alpha)$ is the lowest $V$ satisfying $\left(P_{i}\right)$. For $\delta \geq \widetilde{\delta}(k, \alpha)$, it also satisfies $\left(E_{i}\right)$; the set of $\alpha$-equilibrium values is therefore $[\widetilde{V}(k, \alpha), 1],{ }^{15}$ so that $(1-\widetilde{V}(k, \alpha)) M=$ $\sum_{i} \alpha_{i}\left[\pi^{m}-\tilde{V}(k, \alpha)\right]$ can be interpreted as the largest aggregate punishment that can be sustained. $\frac{\hat{k}_{i}-\alpha_{i}}{\alpha_{i}}$ represents firm $i$ 's proportional gain from deviating, and $\widetilde{\gamma}(k, \alpha)$ is the largest such gain.

\footnotetext{
${ }^{15}$ That is, $\underline{V}(k, \alpha, \delta)$ is independent of $\delta$ for $\delta \geq \widetilde{\delta}(k, \alpha)$.
} 


\subsection{Collusion for endogenous market shares}

We now characterize the optimal market shares for collusion, which minimize $\widetilde{\delta}(k, \alpha)$ and thus $\widetilde{\gamma}(k, \alpha) /(1-\widetilde{V}(k, \alpha))$. The denominator in the latter expression is maximal when $\widetilde{V}(k, \alpha)$ is minimized, which is obtained for market shares that are proportional to minmax profits. The numerator $\widetilde{\gamma}(k, \alpha)$ is instead minimal when market shares are proportional to (relevant) capacities. Since minmax profits are not in general proportional to capacities, there is a conflict between decreasing $\widetilde{V}(k, \alpha)$ (punishment concern) and decreasing $\widetilde{\gamma}(k, \alpha)$ (deviation concern). ${ }^{16}$ The following Proposition asserts that the deviation concern is the dominant one and characterizes the minimal threshold for collusion:

Proposition 3.3. If $K_{-n}<M$, the threshold $\widetilde{\delta}(k, \alpha)$ is minimized for $\alpha=\alpha^{*}(k)$ defined by

$$
\alpha_{i}^{*}(k) \equiv \frac{\hat{k}_{i}}{\hat{K}} M
$$

and:

$$
\delta^{*}(k) \equiv \widetilde{\delta}\left(k, \alpha^{*}(k)\right)=\frac{\hat{k}_{n}}{\hat{K}} .
$$

\footnotetext{
${ }^{16}$ Given $K_{-n}<M$, the only instance where this conflict disappears is when firms have the same capacity (symmetric configuration).
} 
Proof. The proof builds again on the necessary conditions outlined in Lemma (3.1). Adding-up $\left(P_{n}\right)$ and $\left(E_{n}\right)$ yields:

$$
\alpha_{n} \geq(1-\delta) \hat{k}_{n}+\delta\left(M-K_{-n}\right)
$$

or:

$$
\delta \geq \frac{\hat{k}_{n}-\alpha_{n}}{\hat{K}-M}
$$

Similarly, adding-up $\left(P_{n}\right),\left(E_{1}\right) \ldots\left(E_{n-1}\right)$ and using $V \geq \frac{M-K_{-n}}{\alpha_{n}}$ yields:

$$
\begin{aligned}
M-\alpha_{n} & \geq(1-\delta) K_{-n}+\delta\left(M-\alpha_{n}\right) \frac{M-K_{-n}}{\alpha_{n}} \\
\Longleftrightarrow \quad M \delta\left[\alpha_{n}-\left(M-K_{-n}\right)\right] & \geq \alpha_{n}\left[\alpha_{n}-\left(M-K_{-n}\right)\right] \\
\Longleftrightarrow \quad M \delta & \geq \alpha_{n},
\end{aligned}
$$

since (3.2) implies $\alpha_{n}>M-K_{-n}$. Combining (3.3) and (3.4) yields:

$$
\delta \geq \max \left\{\frac{\alpha_{n}}{M}, \frac{\hat{k}_{n}-\alpha_{n}}{\hat{K}-M}\right\} .
$$

Since $\left(\hat{k}_{n}-\alpha_{n}\right) /(\hat{K}-M)$ decreases with $\alpha_{n}$ and equals $\hat{k}_{n} / \hat{K}$ for $\alpha_{n}=$ $\hat{k}_{n} M / \hat{K}$, the right-hand side of $(3.5)$ is at least equal to $\hat{k}_{n} / \hat{K}$. And this lower bound is achieved if and only if $\delta=\alpha_{n}=\left(\hat{k}_{n}-\alpha_{n}\right) /(\hat{K}-M)$, i.e., if (3.3) and (3.4), and thus all conditions $\left(E_{i}\right)_{i=1, \ldots, n}$, are satisfied with equality, implying $\alpha=\alpha^{*}(k)$. 
To conclude it suffices to check that conditions $\left(P_{i}\right)_{i=1, \ldots, n-1}$ are also satisfied when $\alpha=\alpha^{*}(k)$. They are trivially satisfied if $\hat{K}_{-i}>M$ (since firm $i$ 's minmax is then zero). Otherwise, when $\alpha=\alpha^{*}(k),\left(P_{i}\right)$ can be written as

$$
\delta \frac{M}{\hat{K}} \geq \frac{M-\hat{K}_{-i}}{\hat{k}_{i}}=1-\frac{\hat{K}-M}{\hat{k}_{i}} .
$$

Since the right-hand side increases with $i,\left(P_{i}\right)$ follows from $\left(P_{n}\right)$.

The optimal market shares $\alpha_{i}^{*}$ thus minimize $\widetilde{\gamma}(k, \alpha)$, the largest proportional gain from deviating, even if this does not maximize the punishment $1-\widetilde{V}(k, \alpha) .{ }^{17}$

Comment 1: Restriction to $\alpha$-equilibria Focussing on $\alpha$-collusive equilibria a priori restricts the scope for collusion by limiting the punishments that can be inflicted on deviating firms. The punishments achieved with $\alpha$-equilibria are however at least as effective as those generated by reverting to a Nash equilibrium of the competitive stage game, since those profits, $\pi_{i}^{N}$, necessarily satisfy: ${ }^{18}$

$$
\pi_{i}^{N} \geq \alpha_{i}^{*}(k) \widetilde{V}\left(k, \alpha^{*}(k)\right)=\left(M-K_{-n}\right) \hat{k}_{i} / \hat{k}_{n}
$$

Thus the threshold $\delta^{*}(k)$ is -weakly- lower than for standard trigger-strategy equilibria. $^{19}$

\footnotetext{
$17 \widetilde{\gamma}$ is not differentiable at $\alpha=\alpha^{*}$; any change away from $\alpha=\alpha^{*}$ thus generates a first-order increase, which dominates any possible benefit from a higher punishment $1-\widetilde{V}(\beta, \alpha)$.

${ }^{18}$ The largest firm gets at least $M-K_{-n}>0$ by charging $p_{n}=1$ with probability 1 and will thus never charge a price below $\underline{p}=\left(M-K_{-n}\right) / \hat{k}_{n}$. But then, by charging a price slightly below $\underline{p}$ any firm $i<n$ can sell at full capacity and get $\left(M-K_{-n}\right) k_{i} / \hat{k}_{n}=\left(M-K_{-n}\right) \hat{k}_{i} / \hat{k}_{n}$.

${ }^{19} \mathrm{In}$ the case of a duopoly $(n=2)$, the punishment profits used here, $\alpha_{i}^{*} V^{*}=$
} 
Furthermore, a firm can never be punishmed below its minmax; therefore, $\delta^{*}(k) \geq \delta(k) \geq \underline{\delta}(k)$, where $\underline{\delta}(k)$, the threshold for collusion if minmax profits were implementable, is characterized by

$$
\frac{\underline{\delta}(k)}{1-\underline{\delta}(k)}=\frac{K-1}{1-\underline{\pi}(k)}
$$

where $\underline{\pi}(k) \equiv \sum_{i} \underline{\pi}_{i}(k)$ denotes the "aggregate" minmax profit. There are two instances, however, where minmax profits can be implemented through $\alpha$-equilibria; this is when: (i) firms are symmetric $\left(k_{i}=K / n\right)$; and (ii) $K_{-n} \geq M$, in which case $\underline{\pi}_{i}(k)=0$ for all $i=1, \ldots, n .{ }^{20}$ Therefore, in both instances $\delta^{*}(k)=\delta(k)=\underline{\delta}(k)$, that is, the restriction to $\alpha$-equilibria does not limit the scope for collusion.

Comment 2: Symmetric capacities As just mentioned, for symmetric capacities our analysis characterizes the best collusive equilibria, using minmax profits as punishments. If $k_{i}=K / n>M$, there are no effective capacity constraints and a small change in market size or a uniform increase in capacity has no effect on $\left(M-K_{-n}\right) \hat{k}_{i} / \hat{k}_{n}$, actually coincide with the Nash equilibrium profits. In the case of a triopoly $(n=3)$, for $K_{-3}<M<K$ Nash equilibrium profits coincide with the punishments used here if $k_{3}=M$ or $K_{-1} \leq M$ whereas, if $k_{3}<M<K_{-1}$, they coincide for $i=2,3$, but $\pi_{1}^{N}>\alpha_{1}^{*} V^{*}=\left(M-K_{-3}\right) k_{1} / k_{3}$ (proof available upon request), so that $\alpha$-collusive equilibria are strictly more effective for collusion than trigger strategies based on reversal to Nash.

${ }^{20}$ For the symmetric case, it suffices to note that the "best" collusive $\alpha$-equilibrium (achieved for $\left.\alpha_{i}=\hat{k}_{i} / \hat{K}\right)$ punishes the largest firm by its minmax profit; this therefore applies to all firms when they are symmetric. For the latter case $\left(K_{-n} \geq M\right)$, it suffices to note that the collusive equilibrium characterized in the previous section, where all firms charge zero price after a deviation, can be constructed as an $\alpha$-equilibrium (market shares being irrelevant when prices are zero). 
collusion: $\delta(k)=\delta^{*}(k)=1-1 / n$. If instead $k_{i}=K / n<M$, each firm faces a capacity constraint and a decrease in the market size or a uniform increase in capacity increases the gains from deviating, but may also enhance punishments when $K_{-n}=(n-1) K / n<M$. We must therefore distinguish two cases (see Figure 1):

\section{Place Figure 1 here \\ Figure 1}

Critical level for the discount factor for symmetric firms $n$ : number of firms, $K$ : total capacity, $M$ : market size

- If $K / n<M<(n-1) K / n$, any $(n-1)$ firms can cover the market and punishments are maximal (zero profits); a decrease in the market size or a uniform increase in capacity thus only increases the aggregate gain from deviations, making collusion more difficult: $\delta(k)=\delta^{*}(k)=1-M / K{ }^{21}$

- If $M>(n-1) K / n$, a decrease in the market size or a uniform increase in capacity also enhances punishment possibilities, by increasing the total (relevant) capacity of any $(n-1)$ firms; this favourable effect on punishments exactly offsets the adverse effect on gains from deviations: $\delta(k)=\delta^{*}(k)=$ $1 / n$, independently of $M$ or $K .^{22}$

\footnotetext{
${ }^{21}$ The first case cannot occur in a duopoly situation.

${ }^{22}$ The favourable effect on punishment possibilities could however dominate if the demand was downward sloping - see for example Brock-Scheinkman (1985).
} 
Comment 3: Market shares For a discount factor $\delta=\delta^{*}(k)$, collusion may only be supported for market shares equal to $\alpha^{*}(k)$ and firms with a larger capacity thus obtain a larger share of the market. As the discount factor increases, the range of market shares for which collusion can be supported increases. To fix ideas, consider for instance the case of a duopoly where $M \geq k_{2}>k_{1}>M / 2$ (that is, the smaller firm could still potentially get the largest market share). The range of market shares that allow for perfect collusion are of the form $\left\{\left(\alpha_{1}, \alpha_{2}\right)\right.$, $\left.\alpha_{1} \in\left[\underline{\alpha}_{1}(\delta), \bar{\alpha}_{1}(\delta)\right], \alpha_{2}=M-\alpha_{1}\right\}$, where $\underline{\alpha}_{1}(\cdot)$ and $\bar{\alpha}_{1}(\cdot)$ are given by:

\section{Proposition 3.4.}

$$
\begin{aligned}
& \bar{\alpha}_{1}(\delta)=M-k_{2}+\delta(K-M) \text { for } \delta^{*}(k) \leq \delta \leq 1 \\
& \underline{\alpha}_{1}(\delta)= \begin{cases}(1-\delta) M & \text { for } \delta^{*}(k) \leq \delta \leq \widehat{\delta}(k) \equiv \frac{M-k_{1}}{2 M-K}(<1) \\
k_{1}-\delta(K-M) & \text { for } \widehat{\delta}(k) \leq \delta \leq 1\end{cases}
\end{aligned}
$$

For $\delta^{*}=\delta^{*}(k)$, the range reduces to $\alpha_{i}^{*}=\underline{\alpha}_{1}\left(\delta^{*}\right)=\bar{\alpha}_{1}\left(\delta^{*}\right)$, but as $\delta$ increases from $\delta^{*}(k)$ to 1 , the range expands on both sides. In the limit case $\delta=1, \bar{\alpha}_{i}=k_{i}$ : either firm can sell at full capacity, implying that the smaller firm can have a bigger share than the other one; however, as long as $\delta<\left(k_{2}-M / 2\right) /(K-M)(<1)$, the smaller firm necessarily gets a smaller share (i.e., $\bar{\alpha}_{1}(\delta)<M / 2$ ). Figure 2 represents the evolution of the range of collusive market shares as $\delta$ varies. 


$$
\begin{gathered}
\text { Place Figure 2 here } \\
\text { Figure 2 } \\
\text { Range of market shares allowing collusion }
\end{gathered}
$$

\section{Asymmetric capacities, mergers and collusion}

This section draws the implications of the above analysis for merger and competition policy. We mainly focus on $\alpha$-collusive equilibria, which entails a loss of generality since transfers across firms are constrained and punishments harder to sustain. However, using consistently the same class of equilibria allows us to analyse variations of the threshold in response to changes of capacities. We also explore the analysis of the most general class of collusive equilibria; although we do not provide a full characterization of the threshold $\delta(k)$, two partial characterizations confirm the qualitative insights derived from the analysis of collusive $\alpha$ -equilibria.

Using Proposition (3.3) and since $\delta^{*}(k)=\delta(k)$ is given by (2.1) when $K_{-n} \geq$ $M$, the threshold $\delta^{*}$ can be written as (with $\hat{K}_{-n} \equiv \sum_{i<n} \hat{k}_{i}$ ):

$$
\begin{array}{rlr}
\delta^{*}(k)= & 1-\frac{M}{\hat{k}_{n}+\hat{K}_{-n}} & \text { if } K_{-n}>M, \\
\frac{\hat{k}_{n}}{\hat{K}}=\frac{\hat{k}_{n}}{\hat{k}_{n}+K_{-n}} & \text { if } K_{-n} \leq M .
\end{array}
$$




\subsection{Increase in one firm's capacity}

When small firms are not too small $\left(K_{-n} \geq M\right), \delta^{*}(k)=\delta(k)$ only depends on the aggregate relevant capacity: punishment possibilities are maximal (zero profits) and independent of the distribution of capacity. Capacities thus only affect the incentives to deviate, and any increase in a firm's relevant capacity harms collusion. When instead small firms are indeed small $\left(K_{-n}<M\right)$, punishment possibilities are limited and the distribution of capacity matters. The proof of Proposition (3.3) shows that the only relevant condition $\left(P_{i}\right)$ is $\left(P_{n}\right)$ : that is, the main problem for collusion is to prevent the largest firm from deviating; collusion is easier when the large firm's incentive to deviate (its relevant capacity $\hat{k}_{n}$ ) decreases, and when small firms' retaliation power (their aggregate capacity $K_{-n}$ ) increases (see Figure 3). ${ }^{23}$

\footnotetext{
${ }^{23}$ When small firms have very little capacity, the total industry (expected) profits are close to the monopoly level even in the static Nash equilibrium - and collusion is therefore not a very relevant issue. Assuming that perfect collusion is sustainable when small firms are not too small, the description of the best "collusive" (expected) price, as a function of the capacity of the small firms, is as follows: the best collusive expected price remains at $p^{m}=1$ as long as small firms are not too small, and drops to the level of the static Nash equilibrium, which however increases when the capacity of the small firms decrease (and gets back to $p^{m}=1$ when small firms disappear).
} 


\section{Place Figure 3 here}

Figure 3

Critical level for the discount factor for asymmetric firms

$k_{n}$ : total capacity of the largest firm,

$K_{-n}$ : total capacity of the smaller ones,

M: market size.

\subsection{Variations in demand}

When small firms are not too small $\left(K_{-n} \geq M\right)$, a reduction in demand hurts collusion. ${ }^{24}$ In contrast, when small firms are really small $\left(K_{-n}<M\right)$, a reduction in demand either has no impact on collusion (if $k_{n}<M$, since the demand reduction then does not affect firms' relevant capacities: $\hat{k}_{i}=k_{i}$ for every firm $i$ ), or is beneficial to collusion (if $K_{-n}<M<k_{n}$, since then the demand reduction still does not affect small firms' retaliation ability but reduces the large firm's incentive to deviate: $\hat{k}_{i}=k_{i}$ for $i<n$ but $\hat{k}_{n}=M$ ).

\subsection{Capacity transfers}

Capacity transfers affect collusion only if they involve the largest firm. The following table recalls the effect on $\delta^{*}$ of a decrease in $k_{i}$ and of an increase in $k_{n}$, and presents the overall impact of the transfer $k_{i} \rightarrow k_{n}$ from firm $i<n$ to firm $n$ :

\footnotetext{
${ }^{24}$ Except if $k_{1} \geq M$, in which case there are no capacity constraints: $\hat{K}=n M$ and $\delta^{*}(K)=$ $\delta(K)=1-1 / n$.
} 


\section{Place Table 1 here Table 1 \\ Impact of changes in capacity}

When small firms are really small, transferring capacity from a small firm to the largest one hurts collusion ( $\delta^{*}$ increases): it reduces small firms' retaliation ability (since $k_{i}<M$ ) and, moreover, exacerbates the large firm's incentive to deviate if $k_{n}<M$. In contrast, when small firms can cover the entire market $\left(K_{-n}>M\right)$, only the incentives to deviate matter. A similar transfer then cannot hurt collusion since it cannot increase the aggregate relevant capacity: it is neutral if $k_{i}<k_{n}<M$ (since $\hat{k}_{i}+\hat{k}_{n}=k_{i}+k_{n}$ is not affected by the transfer) and may even make collusion easier if the largest firm has excess capacity $\left(k_{i}<M<k_{n}\right)$, since in that case it reduces the small firm's relevant capacity without increasing the large firm's one $\left(\hat{k}_{i}=k_{i}\right.$ but $\left.\hat{k}_{n}=M\right)$.

The next Proposition builds on the above observations and addresses the following question: For a given total capacity $K$ and a given number of firms $n$, what are the distributions of capacity that most facilitate collusion? The answer depends on the comparison between the market size $M$ and the maximal capacity of the $n-1$ smaller firms, $\frac{n-1}{n} K$ :

Proposition 4.1. Best capacity distributions for collusive $\alpha$-equilibria. 
For any $K$ and $n \geq 2$, the set $\mathcal{K}^{*}(K, n)$ of distributions that minimize $\delta^{*}(k)$ is given by:

i) If the total capacity is sufficiently small $\left(K \leq \frac{n}{n-1} M\right)$, then:

$$
\mathcal{K}^{*}(K, n)=\left\{k^{S} \equiv(K / n, \ldots, K / n)\right\}
$$

ii) If instead the total capacity is large $\left(K>\frac{n}{n-1} M\right)$, then:

- If $K \leq 2 M$ or $n=2, \mathcal{K}^{*}(K, n)$ consists of all distributions that allow the $n-1$ smallest firms to cover the entire market $\left(K_{-n} \geq M\right)$.

- If $K>2 M$ and $n \geq 3, \mathcal{K}^{*}(K, n)$ consists of all the asymmetric distributions that give a total capacity $K_{-n}=M$ to $n-1$ small firms and the entire extra capacity to a large firm $\left(k_{n}=K-K_{-n}>M\right)$.

Proposition 4.1 is driven by two principles: to facilitate collusion, 1) the retaliation possibilities of the smallest firms should be maximized, i.e. the aggregate capacity of the smallest firms should be increased, up to market size if possible; 2) among the distributions of capacities that maximize retaliation possibilities, the gains from deviating should be minimized.

When the total capacity is small $\left(\frac{n-1}{n} K \leq M\right)$, the smallest $(n-1)$ firms cannot cover the market; in that case, the main problem is to discipline the largest firm; starting from any asymmetric situation, transferring some capacity from 
the largest firm to a small one then both enhances the small firms' retaliation power and limits the large firm's incentives to deviate: the best distribution of capacities is therefore the symmetric one, $k^{S}$. When instead the total capacity is large enough $\left(\frac{n-1}{n} K>M\right)$, retaliation possibilities are maximized whenever the small firms can cover the market $\left(K_{-n} \geq M\right)$ and the main residual problem is to limit the aggregate incentives to deviate, i.e., to reduce the total relevant capacity $\hat{K}$. When $K>2 M$ and $n \geq 3$, this is achieved only when $K_{-n}$ is precisely equal to the market size, whereas when $K \leq 2 M$ or $n=2$, all distributions satisfying $K_{-n} \geq M$ yield the same relevant capacity $(\hat{K}=K$ when $K<2 M$ and $\hat{K}=2 M$ in the duopoly case).

While Proposition 4.1 restricts attention to collusive $\alpha$-equilibria, the next Proposition shows that the main insights remain valid when considering more general collusive equilibria:

Proposition 4.2. Best capacity distributions for general collusive equilibria.

Fix $K$ and $n$. Then the set $\mathcal{K}(K, n)$ of distributions of capacities that minimize $\delta(k)$ is such that:

i) If $K>2 M, \mathcal{K}(K, n)=\mathcal{K}^{*}(K, n)$.

ii) If $K<\frac{n}{n-1} M, \mathcal{K}(K, n) \supset \mathcal{K}^{*}(K, n)=\left\{k^{S}\right\}$. Moreover, if $\delta=\delta^{*}\left(k^{S}\right)$, for 
any distribution $k$ satisfying:

$$
k_{1}<(1-1 / n) k_{n}
$$

perfect collusion cannot be sustained: $k \notin \mathcal{K}(K, n)$.

When $K>2 M$, collusive $\alpha$-equilibria allow for maximal punishments (zero profits) and the optimal distributions of capacities are unchanged when considering more general collusive equilibria. When $K \leq \frac{n}{n-1} M$, an asymmetry between the capacities of the firms makes collusion more difficult to sustain. The intuition there is that punishing a firm with a low capacity puts an upper bound on the prices other firms may charge. Hence the other firms have to suffer from the punishment they impose on this particular firm. But then, a firm with a large capacity might be reluctant to participate in such a punishment. ${ }^{25}$

\subsection{The impact of mergers on tacit collusion}

We now apply our analysis of collusive $\alpha$-equilibria to the study of mergers and break-ups. The conventional wisdom is that divestitures foster competition, whereas mergers raise antitrust concerns. One argument may be that tacit collusion requires firms to agree on how to support it, and that reaching such a (tacit)

\footnotetext{
${ }^{25}$ Kühn and Motta (2000) obtain a similar insight in a context where firms differ in the range of varieties they offer. There again, and for a similar reason, an asymmetry in the distribution of varieties among the firms makes collusion more difficult to sustain.
} 
agreement may be more difficult when the number of firms is larger (e.g., firms may find it more difficult to agree on market shares). Compte and Jehiel (1996) supports this intuition in the context of a non-cooperative bargaining model. We will abstract from such issues here, and focus on the sole impact of the distribution of capacities on collusive ( $\alpha$-)equilibria.

Our analysis emphasizes two distinct elements. On the one hand, a merger reduces the number of competitors, which tends to facilitate collusion: This wellknown effect dominates when capacity constraints are not too severe. On the other hand, a merger exacerbates the asymmetry in capacities when it involves the largest firm. This tends to hurt tacit collusion, and this effect dominates when the capacity constraints are more severe or their distribution is very asymmetric. ${ }^{26}$

In the absence of any capacity constraint $\left(k_{i} \geq M\right.$, and thus $\hat{k}_{i}=M$, for each firm $i$ ), collusion can be sustained as long as $\delta \geq 1-M / \hat{K}=1-1 / n$. The standard result then applies: any merger facilitates collusion because it reduces the number of competitors, whereas any break-up of a firm makes collusion more difficult to sustain, since the aggregate relevant capacity necessarily increases. ${ }^{27}$ The same

\footnotetext{
${ }^{26}$ Note that when $K_{-n} \geq M$, the analysis applies to the most general class of collusive equilibria as well as to the class of symmetric ones. When $K_{-n}<M$, the discussion that follows is based on the analysis of $\alpha$-equilibria; however, Proposition 4.2 suggests that even for more general collusive equilibria a merger involving the largest firm, which exacerbates the asymmetry in the distribution of capacities, is still likely to hurt collusion.

${ }^{27}$ If for example firm $i$ is broken-up into two firms $i$ and $i^{\prime}$ with capacities $k_{i}^{\prime}$ and $k_{i^{\prime}}^{\prime}$, then $k_{i}^{\prime}+k_{i^{\prime}}^{\prime}=k_{i}>M$ implies $\hat{k}_{i}^{\prime}+\hat{k}_{i^{\prime}}^{\prime}>M=\hat{k}_{i}$.
} 
argument carries over to situations where firms are capacity-constrained but not too much so $\left(K_{-n} \geq M\right)$. In that case, the maximal punishment (zero profits) can still be imposed on any firm, and only the incentives to deviate matter, summarized by the total relevant capacity $\hat{K}$; perfect collusion can be sustained as long as $\delta \geq 1-M / \hat{K}$ (but $\hat{K} / M$ may now be lower than $n$ ). Since a merger can only decrease the total relevant capacity, it can only facilitate collusion: more precisely, any merger leading to the creation of a firm "large enough" to cover the entire market facilitates collusion, while the other mergers have no impact on collusion. Conversely, forcing any such large firm to divest part of its capacity always makes collusion more difficult to sustain (provided that the divested capacity is not given to a firm already large enough to cover the market), while the break-up of a small firm that cannot initially cover the entire market has no impact on collusion.

In contrast, when capacity constraints are more severe $\left(K_{-n}<M\right)$, any merger involving the largest firm hurts tacit collusion. The reason is that, as already emphasized, the key issue for tacit collusion is then to prevent this large firm from deviating: but such a merger precisely reduces small firms' ability to retaliate (by transferring some of their capacity to the largest firm), and may moreover exacerbate the large firm's gains from deviation if it was initially capacity-constrained. In contrast, forcing the large firm to divest part of its capacity $k_{n}$ might facilitate 
collusion.

Policy implications. This analysis suggests merger guidelines that substantially differ from those inspired by static analyses. In particular, for a given number of firms, the Herfindahl or other standard concentration tests tend to predict that a more symmetric configuration is more likely to be competitive (the Herfindahl index is minimal for a symmetric configuration). Similarly, the static Nash equilibrium industry-wide profits often decrease with symmetry. ${ }^{28}$ The above analysis instead suggests that asymmetry may be pro-competitive, as it may hurt tacit collusion. A sufficiently asymmetric configuration may even more than compensate for a reduction in the number of firms: If $K_{-n}<M$, any merger involving the large firm hurts collusion and may thus benefit competition since, although it reduces the number of competitors, it exacerbates the asymmetry between them (the Herfindahl test would in contrast advise that the pre-merger situation is more favourable to competition). The above analysis also casts some doubt on standard merger remedies, which consist in divesting some of the capacity of the merged firm and transferring it to other competitors: Such remedy, which tends to maintain a reasonable amount of symmetry between the competitors, avoids the creation

\footnotetext{
${ }^{28}$ Suppose for example that a capacity $K$ is distributed among $n$ firms who play the static price competition game described above. Each firm $i$ gets $\max \left\{0, M-\frac{n-1}{n} K\right\}$ if the distribution is symmetric and at least $\max \left\{0,\left(M-\hat{K}_{-n}\right) \hat{k}_{i} / \hat{k}_{n}\right\}$ otherwise (see footnote 18). The industrywide profits are thus mimized when the capacity $K$ is distributed evenly among the $n$ firms.
} 
of a "dominant position" but may help tacit collusion. The above analysis thus suggests that merger policy should treat very differently "single dominance" cases and "collective dominance" cases. The following discussion of the Nestlé-Perrier case illustrates these issues.

\section{An analysis of the Nestlé-Perrier merger}

On February 251992 Nestlé, which manufactures and sells food products and is active in the French bottled water sector with two major brands (Vittel and Hepar) notified to the EEC commission a public bid for $100 \%$ of the shares of source Perrier SA which is mainly active in the manufacture and distribution of bottled waters. The Commission decision ${ }^{29}$ mentions that in 1991, before the merger, the total annual volume of the French bottled water market was 5.25 billion litres. At the time of the merger Nestlé sold annually 900 million litres on the French bottled market (market share: 17.1\%), Perrier sold 1.885 million litres ( market share 35.9\%), BSN sold 1.207 million litres (market share 23\%). Other suppliers sold 1.258 million litres (total market share 24\%). ${ }^{30}$ In the rest of our

\footnotetext{
${ }^{29}$ Nestlé/Perrier, Commission Decision of 22 July 1992, Case NoIV/M190.

${ }^{30}$ For confidentiality reasons, the decision does not indicate individual market shares and production capacities. However, these shares and capacities can be roughly estimated for each of the main suppliers, using information provided in different recitals of the decision - see Compte-Jenny-Rey (1997). Due to space constraints the method used is not detailed here and only the results are mentioned.
} 
analysis we will ignore the smaller producers. ${ }^{31}$

According to the EU merger regulation a concentration which creates or strengthens a dominant position as a result of which effective competition would be significantly impeded in the common market or in a substantial part of it is incompatible with the common market. There is little doubt, when one considers the case law and the importance that the Commission attaches to the distribution of market shares in merger cases, that the parties to the merger thought that the Commission was likely to oppose the takeover of Perrier by Nestlé on the ground that it created a dominant position for the merging parties. ${ }^{32}$

However, Nestlé and Perrier had also agreed, subject to Nestlé acquiring control of Perrier, to transfer Volvic (a major still mineral source of Perrier) to BSN. With this transfer taken into consideration the post merger situation would have been a balanced duopoly ${ }^{33}$ and the merging parties may have hoped to avoid the

\footnotetext{
${ }^{31}$ Indeed in recital 129 of its decision the Commission notes: "Local spring and mineral waters are too small and dispersed to constitute a significant alternative to the national waters. As examined (above), none of these companies constitutes a sufficient price-constraining competitive force (...).".

${ }^{32}$ In recitals 132-134, the Commission stated that such a merger would have led the merging firms to have approximately $53 \%$ ( by volume) of the bottled water market, more than twice the market share of the next biggest competitor. It added that the merged entity would have had capacities exceeding the volume of the total bottled water market, would have had a major advantage over its main competitor in terms of the number of major sources held both on the still and on the sparkling mineral water segments and would not have been constrained either by local spring water sources, by retailers or wholesalers or by potential competition. It concluded that "the reduction from three to two suppliers (duopoly) is not a mere cosmetic change in the market structure. The concentration would lead to the elimination of a major operator who has the biggest capacity reserves and sales volumes in the market."

${ }^{33}$ Cf. recital 123: " After the merger , there would remain two national suppliers on the
} 
risk of having the Commission block the takeover since after the merger neither one of the two remaining major operators could be considered to hold a dominant position.

However, the Commission which for a while had sought to expand the scope of the EU merger regulation used this takeover as a test case to put forth a new interpretation of the merger regulation. It claimed that the regulation should be construed not only as prohibiting mergers which create or strengthen a dominant position for the merging firms but also as prohibiting mergers which create or strengthen an "oligopolistic dominance". For the Commission such a creation or strengthening would occur if "there is already before the merger weakened competition between the oligopolists which is likely to be further weakened by a significant increase in concentration and if there is no sufficient price constraining competition from actual or potential competition coming from outside the oligopoly".

The Commission then reasoned that competition had been weak on the bottled water market even before the merger. It based its conclusion on three main facts "the high degree of market parallelism over a long period of time, the very high

market which would have similar capacities and similar market shares ( symmetric dupoly)". Indeed the sales of Nestlé+Perrier-Volvic, on the one hand, and of BSN + Volvic, on the other hand, would have been roughly equal to 2 billion liters each and each would have had a market share of $38 \%$. 
production-cost margin, and the large gap between ex-works price of national mineral waters and local spring waters". It further stated that "the reduction from three to only two national suppliers would make anticompetitive parallel behaviour leading to collective abuses much easier". This last assessment was based on two main types of considerations, namely:

- the two players remaining in the market would be similar in size and nature and neither one would enjoy a significant cost advantage over the other; technology was mature and $\mathrm{R} \& \mathrm{D}$ played no major role;

- the major mineral water suppliers had developed instruments allowing the controlling and the monitoring of each other's behaviour; furthermore demand for mineral water was relatively price inelastic, fringe firms or retailers did not constitute an effective competitive constraint and barriers to entry were high; thus a tacit coordination of pricing policies between BSN and Nestlé would be easily achieved;

Thus, in its decision, the Commission explicitly ruled out allowing the takeover with the transfer of Volvic to BSN (to avoid the strengthening of an oligopolistic dominance) or allowing the merger without the transfer of Volvic to BSN (to avoid single firm dominance for the merged entity). It thus was faced with two choices, either blocking the merger altogether or allowing it subject to divestiture. During 
the proceedings, Nestlé, aware of the fact that the Commission was likely to oppose the merger on the basis of the fact that it was incompatible with the Common Market, agreed to meet the requirements of the Commission by committing itself to selling various well known brands (among them Vichy, Thonon, Pierval, Saint Yorre) and three billion litres of water capacity to a third party so that this third party could become an active player on the market. Subject to the compliance with this commitment, the Commission did not oppose the takeover of Perrier by Nestlé and the subsequent transfer of Volvic to BSN.

This decision raises several questions in relation with our previous discussion of the impact of mergers on tacit collusion. Contrary to what our analysis suggested, the Commission spent relatively little time discussing the consequences of the distribution of capacity obtained through the various solutions on the possibility of collusion among the firms. Similarly, the Commission did not compare the situation created by the commitment it imposed to accept the merger with the pre merger situation. Yet if both situations entail the same number of major actors ( three in both cases) they seem to be characterized by different distributions of capacities.

Drawing from the indications given in the decision and our own estimates, it seems that the distribution of capacity before and after the merger were the 
following (sales and capacities are in million litres, whereas $k_{i} / M$ is the ratio of capacity over market size):

a) Before the merger:

$\begin{array}{cccc} & \text { Sales } & \text { Capacity } & k_{i} / M \\ \text { Nestlé } & 897 & 1,800 & 0.34 \\ \text { Perrier } & 1,885 & (>) 13,700 & >1 \\ \text { BSN } & 1,208 & 1,800 & 0.34\end{array}$

b) After the merger (without the resale of Volvic):

$\begin{array}{cccc} & \text { Sales } & \text { Capacity } & k_{i} / M \\ \text { Nestlé+Perrier } & 2,782 & >15,500 & >1 \\ \text { BSN } & 1,208 & 1,800 & 0.34\end{array}$

c) After the merger (and the resale of Volvic to BSN):

$\begin{array}{cccc} & \text { Sales } & \text { Capacity } & k_{i} / M \\ \text { Nestlé+Perrier-Volvic } & 1,995 & >9,800 & >1 \\ \text { BSN+Volvic } & 1,995 & 7,500 & >1\end{array}$

d) After the merger, the resale of Volvic to BSN and the divestiture to create a new third player:

$\begin{array}{cccc} & \text { Sales } & \text { Capacity } & k_{i} / M \\ \text { Nestlé+Perrier-Volvic-New firm } & ? & >6,800 & >1 \\ \text { BSN+Volvic } & 1,885 & 7,500 & >1 \\ \text { New firm } & ? & 3,000 & 0.57\end{array}$


Using the estimated figures of capacity in relation to the total market size in the different situations, we can compute the minimum discount factor $\delta^{*}$ that allows a collusive equilibrium in each case: ${ }^{34}$

$$
\frac{\text { Place Table } 2 \text { here }}{\text { Table } 2}
$$

Conditions for collusive equilibrium

\section{Several conclusions can be drawn from these figures: ${ }^{35}$}

1) The proposed takeover of Perrier by Nestlé with the resale of Volvic to BSN maximises the scope for collusion: the minimum discount factor for a collusive equilibrium is lower than for any other configuration, including the pre-merger situation.

2) The situation that minimises the scope for collusion is the solution in which

\footnotetext{
${ }^{34}$ The analysis would yield similar results if the total market for bottled water was defined as the sum of the output of the three producers (i.e. 3990 million litres) rather than the sum of the output of the three producers plus the output of the small producers (i.e. 5250 million litres) - see Compte-Jenny-Rey (1997). The results are also very robust to reasonable changes in the assumptions set out above. In particular, capacities would remain substantially higher than the market size in all the cases below where $k_{i} / M>1$.

${ }^{35} \mathrm{We}$ are interested here in the ranking of the threshold $\delta^{*}$ in the various situations, not in its absolute value. Many other factors may affect the actual threshold for collusion. For example, if firms observe or change prices only "every $\tau$ periods", $\alpha$-collusion would be sustainable only if $\delta^{\tau} \geq \delta^{*}(k)$, that is, if

$$
\delta \geq \delta_{\tau}^{*}(k) \equiv\left[\delta^{*}(k)\right]^{1 / \tau}>\delta^{*}(k) .
$$

This factor alone would thus increase the threshold needed for collusion, without altering the comparisons between the situations considered here. The above insights - and the comparisons that follow - are furthermore likely to be robust to the introduction of these other factors: whenever the industry structure opposes a firm with a large excess capacity to firms with rather limited capacities, collusion is likely to be difficult to sustain since the large firm would derive large gains from undercutting its rivals, and the other firms have little retaliation power.
} 
Nestlé and Perrier merge but do not transfer Volvic to BSN: with this transfer, the minimum discount factor jumps from .50 to .75 . This finding is at odds with the Commission decision which states (recital 134): "It cannot be expected that BSN would effectively compete against Nestlé/Perrier since both suppliers would have a strong common interest and incentive to jointly maximize profits". The Commission did not apparently take into consideration that the merged firms (Perrier and Nestlé) would then be able to compete with BSN without fear of large scale retaliation because of the capacity constraint faced by BSN.

The fact that the merger (without the resale of Volvic to BSN) would make a collusive equilibrium more difficult to sustain might also explain why the merging firms planned to resell Volvic to BSN. The (advertised) desire of the merging firms to avoid the creation of a dominant position may have been consistent with their (unadvertised) desire to facilitate collusion.

3) The third conclusion is that the solution chosen by the Commission (i.e., allowing the merger with the resale of Volvic to BSN and additional commitments to spin off capacities equal to 3000 million litres to an independent operator) is intermediate, from the point of view of the sustainability of a collusive solution, between the proposed merger (which maximises the scope for collusion) and the acceptance of the merger without the resale of Volvic (which minimises this scope). 
Even though in the latter case there would have been only two main firms, they would have had a more difficult time sustaining collusion than the three firms (Nestlé, BSN and the new player created by the Commission) will have. The basic reason for this is, first, that in the solution preferred by the Commission neither one of the two largest firms can depart from the collusive equilibrium without exposing itself to retaliation from the other. Since each one of them has a considerable capacity compared with the size of the market, neither one of them can take the risk of retaliation lightly. Second, the new entrant has limited capacities compared to the other two firms and compared to the market and therefore cannot expect to gain by threatening to force competition on them. Altogether, in this solution, the incentives to depart from the collusive solution are not strong.

One of the questions raised by the decision is why did the Commission allow a solution which appears less attractive from the point of view of competition than allowing the merger to proceed without the transfer of Volvic to BSN. There are two possible answers to this question. The first possible answer is that the Commission recognized that the transfer of Volvic to BSN was likely to facilitate a collusive solution but also realized that if it prevented such a transfer, Nestlé might challenge the decision (by taking its case to the European Court of Jus- 
tice) on the basis that the merger regulation did not apply to the creation or strengthening of oligopolistic dominance. Because the Commission did not want to face such a challenge, it may have deliberately promoted a solution which was less favourable from point of view competition than what could be achieved but satisfied Nestlé sufficiently so that it would not pursue the matter. Indeed neither Nestlé, although it voiced strong objections against the extensive interpretation of the merger regulation used by the Commission, nor BSN, for obvious reasons, challenged the decision. The second possible answer is that the Commission did not take into account the impact of the distribution of production capacity on the sustainability of collusion and focused instead solely on the number of major players. 


\section{A. Proofs}

\section{A.1. Proof of Lemma 3.1}

i) By definition, in a collusive $\alpha$-equilibria, after any history of prices $h^{t}$, all firms charge the same price $p\left(h^{t}\right)$ and firm $i$ 's market share is equal to $\alpha_{i}$. This implies that after any history, firms' continuation values remain proportional to their original market shares, and are thus of the form $\alpha_{i} V\left(h^{t}\right)$ for some value $V\left(h^{t}\right)$. Consider the lowest continuation equilibrium value, $V \equiv \inf V\left(h^{t}\right)$. After any history $h^{t}$, firm $i$ 's per period continuation equilibrium value $\alpha_{i} V\left(h^{t}\right)$ cannot be lower than its minmax payoff $\underline{\pi}_{i}$, which it can secure by charging the monopoly price forever; this implies $\left(P_{i}\right)$.

Now consider the equilibrium path of prices $\left\{p^{t}\right\}_{t \geq 0}$. At any date $t$ on the equilibrium path, player $i$ 's continuation value is equal to $\alpha_{i} V^{t}$ where ${ }^{36}$

$$
V^{t}=(1-\delta) \sum_{s \geq 0} \delta^{s} p^{t} 1_{p^{t} \leq 1}
$$

At any date $t$ for which $p^{t} \leq 1$, if firm $i$ deviates and slightly undercuts the price $p^{t}$, it gets $\hat{k}_{i} p^{t}$ in the current period and at least $\alpha_{i} V$ in the following ones. Ruling out such a deviation imposes:

$$
\alpha_{i} V^{t} \geq(1-\delta) \hat{k}_{i} p^{t}+\delta \alpha_{i} V, \forall t \text { such that } p^{t} \leq 1 .
$$

\footnotetext{
${ }^{36} 1_{p^{t} \leq 1}$ equals 1 if $p^{t} \leq 1$ and 0 otherwise.
} 
Taking the supremum over the dates $t$ for which $p^{t}$ is no greater than 1 on the left side, then on the right side, yields

$$
\alpha_{i} \bar{V} \geq(1-\delta) \hat{k}_{i} \bar{p}+\delta \alpha_{i} V
$$

where $\bar{V}=\sup _{t, p^{\prime} \leq 1} V^{t}$ and $\bar{p}=\sup _{t, p^{\prime} \leq 1} p^{t}$. Equation (A.1) implies $\bar{V} \leq \bar{p}$, which combined with (A.2) further implies

$$
\left[\alpha_{i}-(1-\delta) \hat{k}_{i}\right] \bar{p} \geq \delta \alpha_{i} V
$$

Since $V$ is non-negative and since $\bar{p} \leq 1$, (A.3) also holds for $\bar{p}=1$, which proves that condition $\left(E_{i}\right)$ holds.

ii) Note first that adding conditions $\left(E_{i}\right)$ implies:

$$
\delta(1-V) \sum_{i} \alpha_{i} \geq(1-\delta)\left(\hat{K}-\sum_{i} \alpha_{i}\right)
$$

and $\sum_{i} \alpha_{i} \leq M<\hat{K}$ thus implies $V<1$. We now prove that $V$ is an equilibrium continuation value.

If $V=0$, conditions $\left(P_{i}\right)$ imply that $\underline{\pi}_{i}=0$ for all $i=1, \ldots, n$. In that case, $p_{i}=0$ is a Nash equilibrium of the static game, which in turn implies that $V=0$ is sustainable.

If $V>0$, we construct the following punishment path $\left(p^{t}\right.$ denotes the price 
charged in the $t^{\text {th }}$ period of the punishment):

$$
\begin{aligned}
& p_{t}=0 \text { for } t=1, \ldots, T, \\
& p_{t}=p \text { for } t=T+1, \\
& p_{t}=1 \text { for } t=T+2, \ldots,
\end{aligned}
$$

where $T \geq 0$ and $p \in[0,1]$ are chosen so that $V \equiv \delta^{T}((1-\delta) p+\delta)$. Such $T$ and $p$ always exist since $V \leq 1$. Assuming that deviations from this punishment path are themselves "punished" by returning to the beginning of the punishment path, we now show that no such deviations are profitable. As usual, it suffices to consider one-period deviations and, moreover, since conditions $\left(E_{i}\right)$ rule out deviations in the periods $t>T+1$, we may restrict our attention to the first $T+1$ periods of the punishment path.

At the start of period $t \leq T$ of the punishment path, firm $i$ 's continuation value is $\delta^{-(t-1)} \alpha_{i} V$. By deviating in one of the first $T$ periods, firm $i$ cannot get more than $\underline{\pi}_{i}$ in the current period. Hence such deviations are deterred if:

$$
\delta^{-(t-1)} \alpha_{i} V \geq(1-\delta) \underline{\pi}_{i}+\delta \alpha_{i} V
$$

The most restrictive of these conditions is obtained for $t=1$ and coincides with $\left(P_{i}\right)$. 
In the $(T+1)^{t h}$ period of punishment, the best deviation consists in either charging the monopoly price (if $p$ is low) or in undercutting the rivals (if $p$ is high, namely, if $\alpha_{i} p>\hat{k}_{i}$ ). In the former case, the no-deviation condition is given by (A.4) with $t=T+1$ and is thus implied, too, by $\left(P_{i}\right)$. In the latter case, the no-deviation condition is:

$$
(1-\delta) \alpha_{i} p+\delta \alpha_{i} \geq(1-\delta) \hat{k}_{i} p+\delta \alpha_{i} V
$$

Because $\alpha_{i} \leq \hat{k}_{i}$, it is most restrictive for $p=1$, in which case it is equivalent to $\left(E_{i}\right)$. Hence, under conditions $\left(P_{i}\right)$ and $\left(E_{i}\right)$, the continuation value $V$ is sustainable.

For any other value $V^{\prime} \in[V, 1]$, we can construct a price path similar to the one defined above, with $T \geq 0$ and $p \in[0,1]$ now chosen so that $V^{\prime} \equiv \delta^{T}((1-\delta) p+\delta)$, and use the continuation value $V$ to punish any deviation from this path. The left-hand side of $(A .4)$ becomes $\delta^{-(t-1)} \alpha_{i} V^{\prime}$, and is a fortiorisatisfied. The rest of the argument is unchanged and shows that $V^{\prime}$ is sustainable. To conclude the proof, it suffices to check that conditions $\left\{\left(E_{i}\right),\left(P_{i}\right)\right\}_{i=1, \ldots, n}$ are always relaxed by an increase in the market shares $\alpha$. This is obvious for condition $\left(P_{i}\right)$, and is also true for condition $\left(E_{i}\right)$ since $\delta V \leq V<1$. 


\section{A.2. Proof of Proposition 3.4}

Fix $\delta \geq \delta^{*}(k) \cdot \underline{\alpha}_{1}$ is the value of the following program:

$$
\min _{\alpha_{1}, V} \begin{gathered}
\alpha_{1} \\
\left(P_{1}\right),\left(P_{2}\right),\left(E_{1}\right),\left(E_{2}\right)
\end{gathered}
$$

First, at least two of the four constraints must be binding: if only one of them was binding, it would be possible to slightly decrease $\alpha_{1}$ and adapt $V$ so as to keep satisfying this condition and improve on the objective. Second, $\left(E_{2}\right)$ cannot be binding: Since $\left(\alpha_{1}^{*}(k), V^{*}\right)$ satisfies all constraints, necessarily $\underline{\alpha}_{1} \leq$ $\alpha_{1}^{*}(k)$, which implies $k_{1} / \alpha_{1} \geq k_{2} / \alpha_{2}$, and thus, since $\left(E_{i}\right)$ can be rewritten as $(1-\delta V) /(1-\delta) \geq k_{i} / \alpha_{i},\left(E_{1}\right)$ implies $\left(E_{2}\right)$.

Suppose that $\left(P_{2}\right)$ is not binding. Given the two above remarks, the solution is then given by $\left(P_{1}\right)$ and $\left(E_{1}\right)$ written with equality, that is:

$$
\begin{aligned}
\alpha_{1} & =(1-\delta) k_{1}+\delta\left(M-k_{2}\right) \\
& =k_{1}-\delta(K-M), \\
V & =\frac{M-k_{2}}{\alpha_{1}} .
\end{aligned}
$$

But then $\left(P_{2}\right)$ is equivalent to:

$$
\left[M-k_{1}+\delta(K-M)\right] \frac{M-k_{2}}{k_{1}-\delta(K-M)} \geq M-k_{1}
$$


which itself is equivalent to $\delta \geq \widehat{\delta}=\frac{M-k_{1}}{2 M-K}$.

Similarly, if $\left(P_{1}\right)$ is not binding the solution is given by $\left(P_{2}\right)$ and $\left(E_{1}\right)$ written with equality, that is:

$$
\begin{aligned}
\alpha_{1} & =(1-\delta) M \\
V & =\frac{M-k_{1}}{\delta M} .
\end{aligned}
$$

$\left(P_{1}\right)$ is then equivalent to:

$$
\frac{1-\delta}{\delta}\left(M-k_{1}\right) \geq M-k_{2}
$$

or $\delta \leq \widehat{\delta}$. Hence, $\underline{\alpha}_{1}$ is given by $(A .7)$ for $\delta \leq \widehat{\delta}$ and by $(A .5)$ for $\delta \geq \widehat{\delta}$.

The analysis is similar for $\bar{\alpha}_{1}=M-\underline{\alpha}_{2}$, reversing the indexes 1 and 2: $\underline{\alpha}_{2}$ is equal to $(1-\delta) M$ when $\delta \leq \widehat{\delta}^{\prime} \equiv \frac{M-k_{2}}{2 M-K}$ and to $k_{2}-\delta(K-M)$ for $\delta \geq \widehat{\delta}^{\prime}$; however, the critical threshold $\widehat{\delta}^{\prime}$ is always lower than $\delta^{*}(k)$, so that only the case $\delta \geq \widehat{\delta}^{\prime}$ is relevant, and $\bar{\alpha}_{1}$ is always given by $\bar{\alpha}_{1}=M-\underline{\alpha}_{2}=M-k_{2}+\delta(K-M)$.

\section{A.3. Proof of Proposition 4.1}

i) Assume $\frac{n-1}{n} K>M$. For any distribution of capacities $k$ satisfying $K_{-n}<M$ consider the distribution $k^{\prime}$ such that $k_{n}^{\prime}=k_{n}$ and $k_{i}^{\prime}=K_{-n}^{\prime} /(n-1)$ for $i<n$. Since this modification only affects the capacities of the small firms, $\delta^{*}(k)=\delta^{*}\left(k^{\prime}\right)$. The condition $\frac{n-1}{n} K>M>K_{-n}=K_{-n}^{\prime}$ moreover implies $k_{i}^{\prime}<k_{n}^{\prime}$ for $i<n$, and 
thus a small capacity transfer from the largest firm to a small one would decrease $\delta^{*}\left(k^{\prime}\right)$ (see Table 1$)$

The best capacities thus satisfy $K_{-n} \geq M$, and the threshold $\delta^{*}$ thus only depends on $\hat{K}$, which must be minimized. When $K \leq 2 M$ or $n=2$, the total relevant capacity $\hat{K}$ is the same for any distribution of capacities $k$ satisfying $K_{-n} \geq M$ : when $K \leq 2 M, k_{n}=K-K_{-n}<M$, hence $k_{i}=K_{i}$ and $\hat{K}=K$; when $n=2, \hat{k}_{1}=M=\hat{k}_{2}$, hence $\delta^{*}(k)=1 / 2$.

Assume now $K>2 M$ and $n>2$. For any distribution of capacities $k$ satisfying $K_{-n}=M$ and $k_{n}=K-K_{-n}>M, K_{-n}=k_{n}=M$, hence $\hat{K}=2 M$, whereas $\hat{K}^{\prime}>2 M$ for any distribution $k^{\prime}$ such that $K_{-n}^{\prime}>M$ : Either $k_{n}^{\prime}<M$, in which

case $\hat{k}_{i}^{\prime}=k_{i}$ for all $i$ and thus $\hat{K}^{\prime}=K>2 M$, or $k_{n}^{\prime} \geq M$, in which case $\hat{k}_{n}^{\prime}=M$ and $\hat{K}^{\prime}=M+K_{-n}^{\prime}>2 M$ since $K_{-n}^{\prime}>M$ and $n>2$ imply $K_{-n}^{\prime}>M$.

ii) $\frac{n-1}{n} K \leq M$ implies $K_{-n} \leq M$; hence $\delta^{*}(k)=\hat{k}_{n} / \hat{K}$, which is equal to $1 / n$ for the symmetric distribution $k^{S}$ and strictly higher for any asymmetric distribution.

\section{A.4. Proof of Proposition 4.2}

Assume that perfect collusion can be sustained. Let $v_{i}$ denote firm $i$ 's equilibrium profit. By definition of a perfect collusive equilibrium, all firms charge the 
monopoly price on the equilibrium path, and we must have:

$$
\sum_{i} v_{i}=M
$$

Providing firm $i$ the incentives to charge the monopoly price requires:

$$
v_{i} \geq(1-\delta) \hat{k}_{i}+\delta \underline{\pi}_{i}
$$

since the harshest punishment that can be imposed on firm $i$ in equilibrium cannot be worse than its $\operatorname{minmax} \underline{\pi}_{i}$. Adding the inequalities (A.9) gives a lower bound on $\delta(k)$ :

$$
\delta(k) \geq \underline{\delta}(k) \equiv \frac{\hat{K}-M}{\hat{K}-\underline{\pi}(k)}
$$

i) Assume $K>2 M$. First, observe that $\underline{\delta}(k) \geq 1 / 2$ and that $\underline{\delta}(k)=1 / 2$ if and only if $k_{n}=M$ and $K_{-n} \leq M$ :

- If $k_{n}<M$, then $\hat{k}_{i}=k_{i}$ for $i=1, \ldots, n$ and thus $\hat{K}=K>2 M$, which, together with $\underline{\pi}(k) \geq 0$, yields $\underline{\delta}(k)>1 / 2$.

- If $k_{n}>M$ and $K_{-n}>M$, then $\underline{\pi}(k)=0$ and $\hat{K}>2 M$, and thus $\underline{\delta}(k)=$ $1-M / \hat{K}>1 / 2$.

- If $k_{n}>M$ and $K_{-n} \leq M$, then $\underline{\pi}(k)=M-K_{-n}$ and thus:

$$
\underline{\delta}(k)=\frac{\hat{K}-M}{\hat{K}-\underline{\pi}(k)}=\frac{K_{-n}}{2 K_{-n}}=\frac{1}{2} .
$$


Second, note that the distributions in $\mathcal{K}^{*}(K, n)$ are those satisfying $k_{n}=$ $K_{-n}=M$ and that they yield $\delta^{*}(k)=1 / 2$. Hence, since $\delta^{*}(k) \geq \delta(k) \geq \underline{\delta}(k)$, we have: $\mathcal{K}^{*}(K, n) \subset \mathcal{K}(K, n)$; moreover, all distributions in $\mathcal{K}(K, n)$ must yield $\delta(k)=\underline{\delta}(k)=1 / 2$ and must thus satisfy $k_{n}>M$ and $K_{-n} \leq M$.

Assume now that a distribution satisfying $k_{n}>M$ and $K_{-n}<M$ belongs to $\mathcal{K}(K, n)$, and thus satisfies $\delta(k)=\underline{\delta}(k)(=1 / 2)$. It must then be the case that condition (A.9) is binding for each firm $i$, and thus that the minmax profits can be sustained as equilibrium values. But this is not possible since $k_{n}>M>K_{-n}$ implies $\underline{\pi}_{i}(k)=0$ for $i<n$ and $\underline{\pi}_{n}(k)>0$ : To implement $\underline{\pi}_{i}$, firm $n$ should thus set its price equal to 0 in every period, but then it would obtain a payoff lower than its minmax. Hence $\mathcal{K}(k, n)=\mathcal{K}^{*}(k, n)$.

ii) Assume $K<\frac{n}{n-1} M$. From (A.10):

$$
\underline{\delta}(k)=\frac{\hat{K}-M}{\hat{K}-\sum_{i=1}^{n} \max \left\{0, M-K_{-i}\right\}} \geq \frac{\hat{K}-M}{\hat{K}-\sum_{i=1}^{n}\left(M-K_{-i}\right)}=\frac{1}{n}=\delta^{*}\left(k^{S}\right) .
$$

Hence $k^{S} \in \mathcal{K}(K, n)$. The above inequality also implies that perfect collusion can be sustained for $\delta=1 / n$ only if firms can be punished down to their minmax profits, and if each minmax profit $\underline{\pi}_{i}=\max \left\{0, M-K_{-i}\right\}$ is moreover equal to $M-K_{-i}$, that is, if $K_{-n} \leq \ldots \leq K_{-1} \leq M$, which implies $\hat{k}_{i}=k_{i}(\leq M)$ and $\hat{K}=K{ }^{37}$

\footnotetext{
${ }^{37}$ Except if $n=2$, where $k_{1}<M<k_{2}$ is also a possibility. However in that case, punishing
} 
Assume first that for $\delta=1 / n$ there exists a pure-strategy equilibrium that gives firm 1 its minmax profit $M-K_{-1}$. In the first period of this equilibrium, the price $p_{n}$ charged by firm $n$ cannot exceed $p^{*} \equiv\left(M-K_{-1}\right) / \hat{k}_{1}$, since otherwise by (slightly) undercutting firm $n$, firm 1 would get a market share $\hat{k}_{1}\left(\right.$ since $\left.K_{-n} \leq M\right)$ and a profit $\hat{k}_{1} p_{n}>M-K_{-1}$ (and it can always secure itself its minmax profit in all the following periods). But if firm $n$ charges a price $p_{n} \leq p^{*}$ in this first period, its average discounted payoff will be at most $\hat{k}_{n}\left[(1-1 / n) p^{*}+1 / n\right]$. But if $k_{1}<(1-1 / n) k_{n}, \hat{k}_{1}<(1-1 / n) \hat{k}_{n}\left(\right.$ since $\left.k_{i} \leq M\right)$ and:

$$
\hat{k}_{n}\left[\left(1-\frac{1}{n}\right) p^{*}+\frac{1}{n}\right]=\hat{k}_{n}\left[\left(1-\frac{1}{n}\right)\left(1-\frac{\hat{K}-M}{\hat{k}_{1}}\right)+\frac{1}{n}\right]<M-\hat{K}+\hat{k}_{n}=\underline{\pi}_{n},
$$

which cannot be true in equilibrium. Therefore firm 1 obtains necessarily more than its minmax in equilibrium, and $\underline{\delta}(k)$ is therefore strictly larger than $1 / n$. A similar argument holds for mixed strategy equilibria. ${ }^{38}$

firm 1 down to its minmax would require firm 2 to constantly set its price equal to 0 and thus to get a lower payoff than its minmax.

${ }^{38}$ Assume the price $p_{n}$ charged by firm $n$ exceeds $p>\left(M-K_{-1}\right) / \hat{k}_{1}$ with probability 1 . Then by slightly undercutting the price $p$, firm 1 secures a payoff strictly larger than its minmax, a contradiction. Thus firm $n$ must choose a price below or equal to $p$ with positive probability. The expected profit firm $n$ derives in equilibrium when choosing a price below $p$ in the first period is bounded by $\hat{k}_{n}[(1-1 / n) p+1 / n]$. Since $p$ may be chosen arbitrarily close to $p^{*}$, we obtain that firm $n$ would get an expected equilibrium profit below its minimax $M-K_{-n}$ when $\hat{k}_{1}$ is strictly smaller than $(1-1 / n) \hat{k}_{n}$. 


\section{References}

[1] Abreu, D., 1986. Extremal Equilibria of Oligopolistic Supergames. Journal of Economic Theory 39,191-223.

[2] Abreu, D., 1988. On the Theory of Infinitely Repeated Games with Discounting. Econometrica 56,383-396.

[3] Benoît, J.-P., Krishna, V., 1987. Dynamic Duopolies: Prices and Quantities. Review of Economic Studies 54, 23-35.

[4] Bernheim, B. D., Whinston, M. D., 1990. Multimarket Contact and Collusive Behavior. Rand Journal of Economics 21, 1-26.

[5] Brock, W. A. , Scheinkman, J., 1985. Price Setting Supergames with Capacity Constraints. Review of Economic Studies 52,371-382.

[6] Compte, O., Jehiel, P., 1996. Multi-party Negotiations. Mimeo.

[7] Compte, O., Jenny, P., Rey, P., 1997. Capacity Constraints, Mergers and Collusion. Mimeo.

[8] Davidson, C., Deneckere, R.J., 1984. Horizontal Mergers and Collusive Behavior. International Journal of Industrial Organization 2, 117-132. 
[9] Davidson, C., Deneckere, R.J., 1990. Excess Capacity and Collusion. International Economic Review 31, 521-541.

[10] Fershtman, C., Pakes, A., 1999. A Dynamic Oligopoly With Collusion and Price Wars. Mimeo.

[11] Gertner, R., 1994. Tacit Collusion with Immediate Responses: The Role of Asymmetries. Mimeo.

[12] Kühn, K.-U., Motta, M., 2000. The Economics of Joint Dominance. Mimeo.

[13] Lambson , V. E., 1987. Optimal Penal Codes in Price-Setting Supergames with Capacity Constraints. Review of Economic Studies 54,385-397.

[14] Lambson, V. E., 1994. Some Results on Optimal Penal Codes in Asymmetric Bertrand Supergames. Journal of Economic Theory 62,444-468.

[15] Lambson , V. E., 1996. Optimal Penal Codes in Nearly Symmetric Bertrand Supergames with Capacity Constraints. Journal of Mathematical Economy, forthcoming.

[16] Mason, C. F., Phillips, O.R., Nowell, C., 1992. Duopoly Behavior in Asymmetric Markets: an Experimental Evaluation. Review of Economics and Statistics, 662-670. 
[17] Pénard, T., 1997. Choix de Capacités et Comportements Stratégiques : une Approche par les Jeux Répétés. Annales d'Economie et de Statistique 46,203224. 


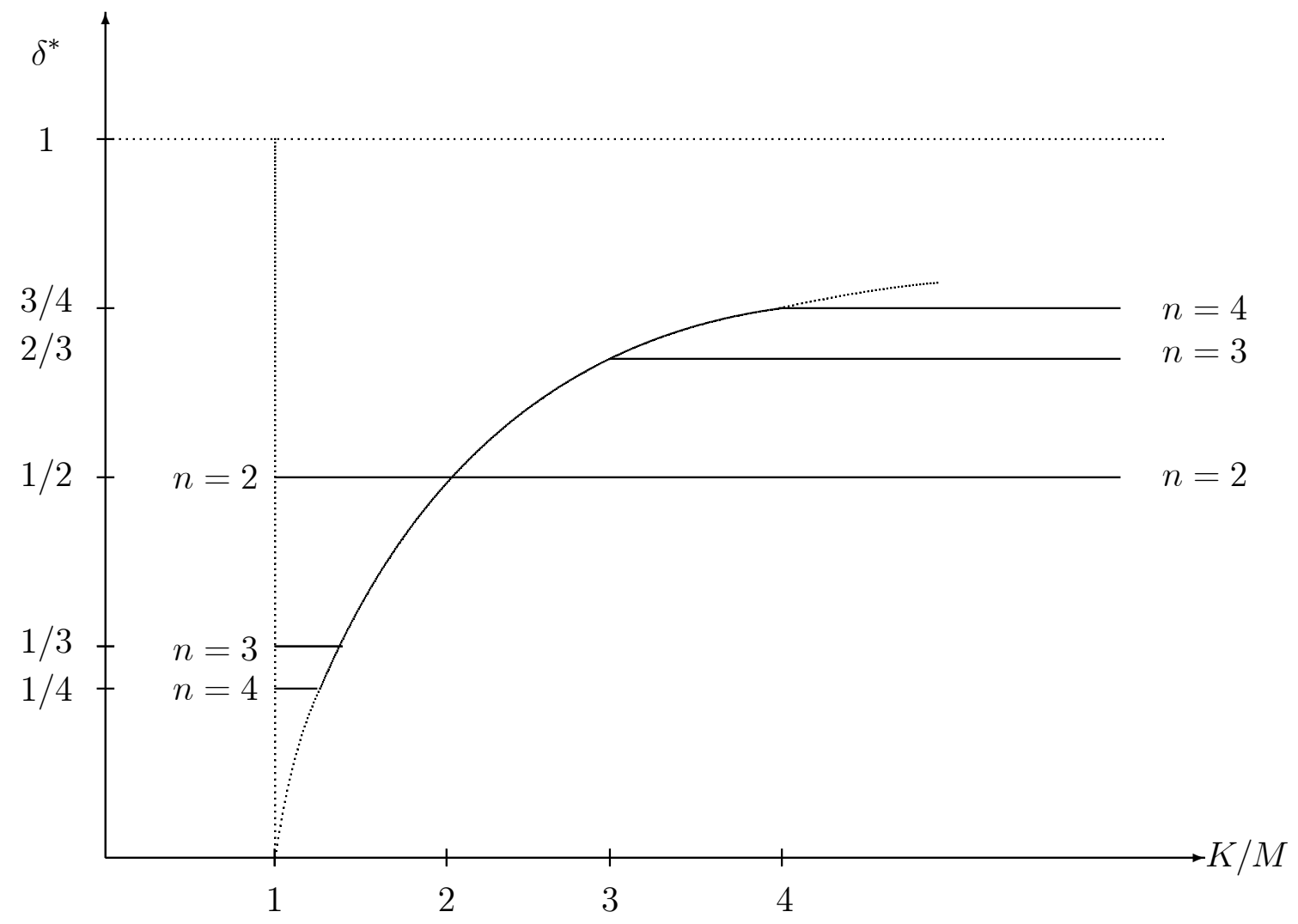

Figure 1

Critical level for the discount factor for symmetric firms $n$ : number of firms, $K$ : total capacity, $M$ : market size 


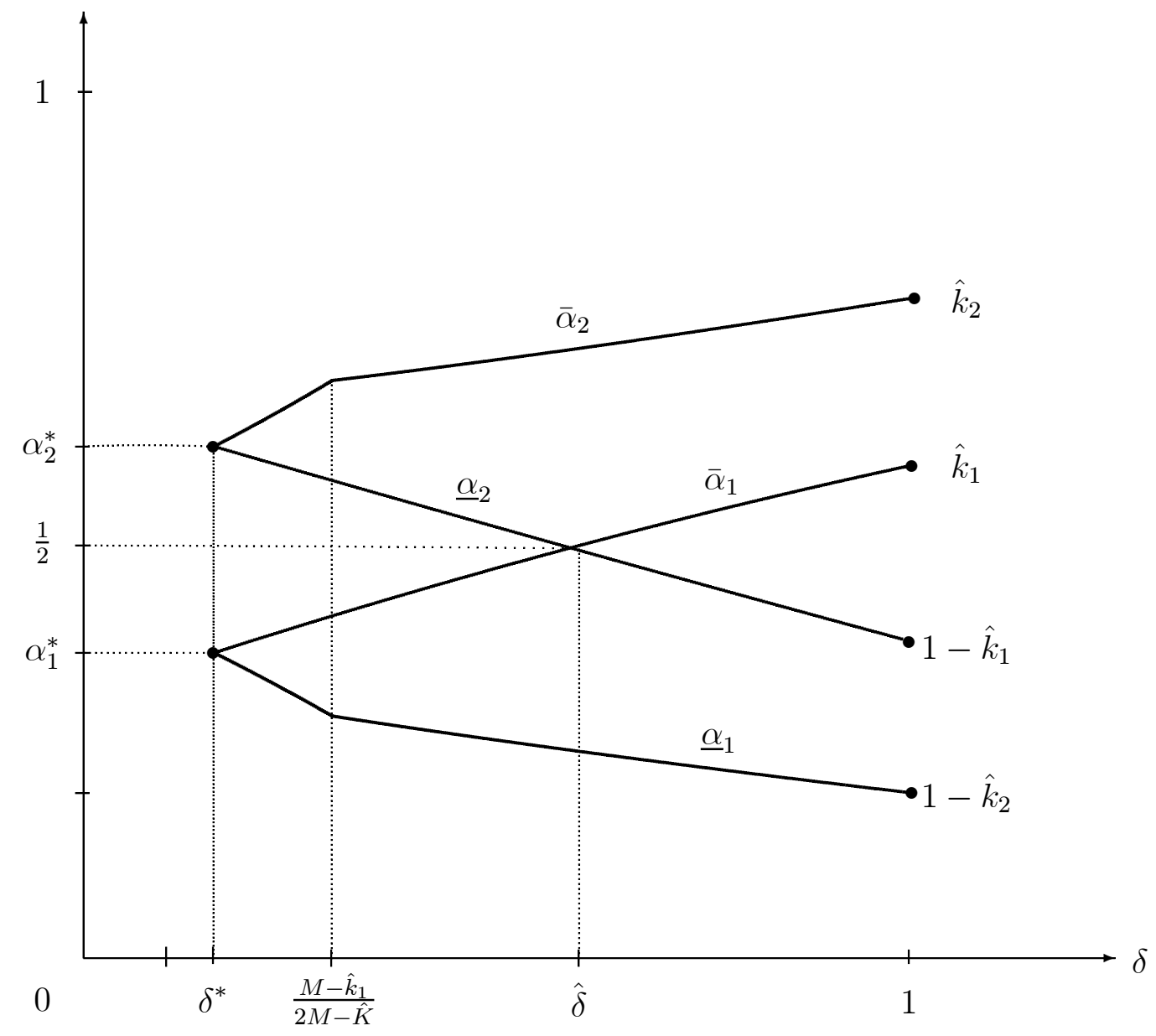

Figure 2

Range of market shares allowing collusion 


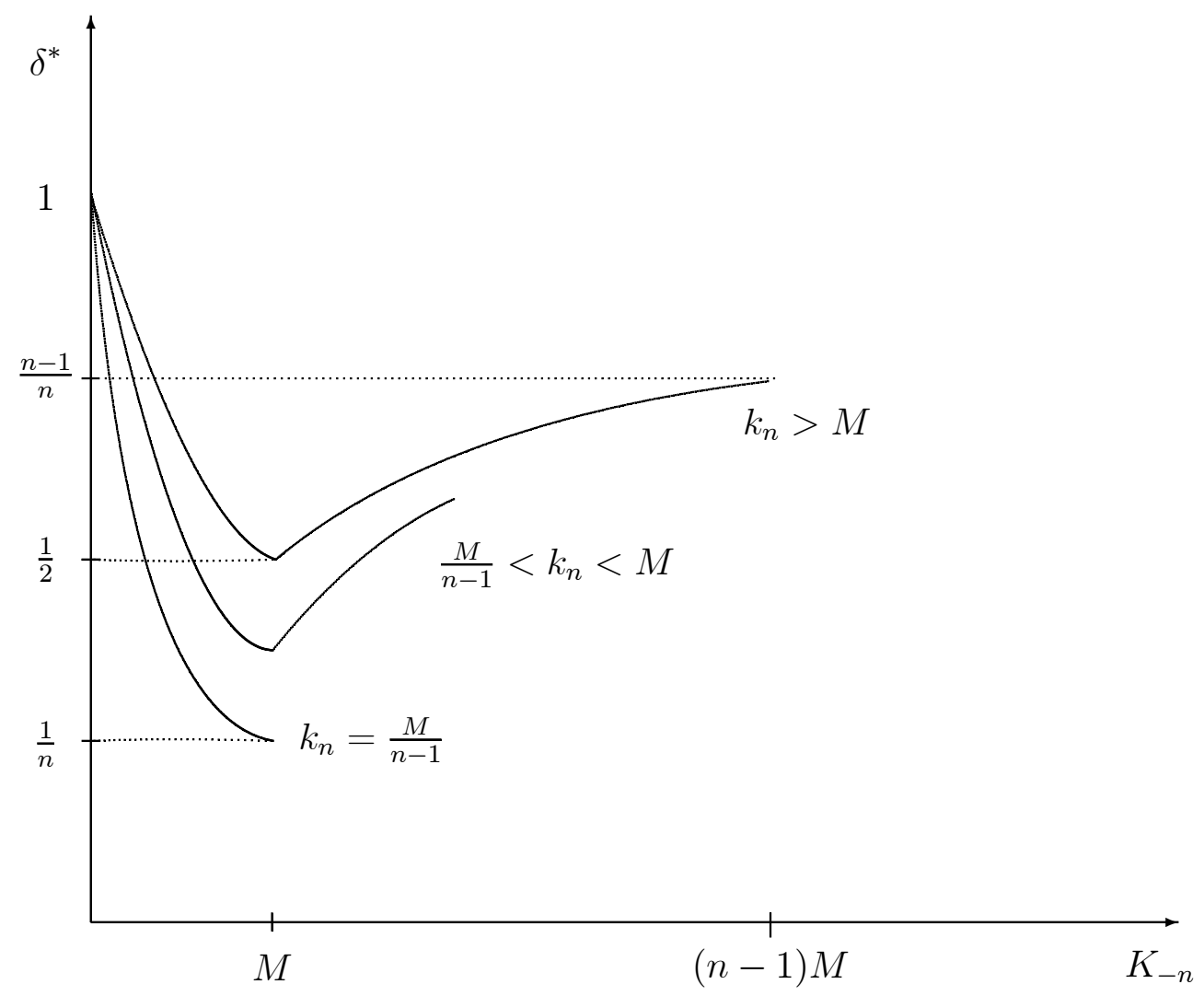

Figure 3

Critical level for the discount factor for asymmetric firms $k_{n}$ : total capacity of the largest firm, $K_{-n}$ : total capacity of the smaller ones. 
$M$ : market size 


\begin{tabular}{|c|c|c|c|c|}
\hline & $\begin{array}{l}K_{-n}<M \\
k_{n}<M\end{array}$ & $\begin{array}{l}K_{-n}<M \\
k_{n}>M\end{array}$ & $\begin{array}{l}K_{-n}>M \\
k_{n}<M\end{array}$ & $\begin{array}{l}K_{-n}>M \\
k_{n}>M\end{array}$ \\
\hline$k_{i} \searrow$ & + & + & - & $-1=$ \\
\hline$k_{n} \nearrow$ & + & $=$ & + & $=$ \\
\hline$k_{i} \rightarrow k_{n}$ & + & + & $=$ & $-1=$ \\
\hline
\end{tabular}

Table 1

Impact of changes in capacity 


$$
k_{1} / M \quad k_{2} / M \quad k_{3} / M \quad k_{4} / M \quad \begin{gathered}
\text { min. discount } \\
\text { for collusion }
\end{gathered}
$$

Before the

merger

0.34

$\begin{array}{lllll}34 & >1 & 0.34 & - & \frac{1}{1.68}=.59 \\ >1 & >1 & - & \frac{1}{2}=.50 \\ >1 & 0.34 & - & \frac{1}{1.34}=.75 \\ >1 & >1 & 0.57 & \frac{1.57}{2.57}=.61\end{array}$

Table 2

Conditions for collusive equilibrium 